\title{
Effect of Oxygen Concentration in the Gas Atmosphere during In Vitro Insemination of Bovine Oocytes on the Subsequent Embryonic Development In Vitro
}

Yoshiyuki TAKAHASHI and Hiroshi KANAGAWA

Laboratory of Theriogenology, Department of Clinical Sciences, Graduate School of Veterinary Medicine, Hokkaido University, Sapporo 060-0818, Japan

(Received 14 July 1997/Accepted 1 October 1997)

ABSTRACT. In vitro matured bovine oocytes were co-incubated with sperm for 18 hr in a droplet of fertilization medium under a gas atmosphere of $5 \% \mathrm{CO}_{2}$ with 5 or $20 \% \mathrm{O}_{2}$. After removing the cumulus cells, they were fixed to examine their fertilization rate, or cultured for another $154 \mathrm{hr}$ in a chemically defined medium under 5\% $\mathrm{O}_{2}$ to determine their development to the blastocyst stage. There was no difference between the 5 and $20 \% \mathrm{O}_{2}$ groups in the fertilization rate. However, the percentage of inseminated oocytes which developed to the blastocyst stage was higher when in vitro insemination was conducted under $5 \% \mathrm{O}_{2}$ compared with that under $20 \% \mathrm{O}_{2}(34.4$ vs. $24.7 \%$, $\mathrm{P}<0.05)$. — KEY WORDS: fertilization, oocyte, oxygen.

J. Vet.Med.Sci. 60(3): 365-367, 1998

Oxygen tension in the female reproductive tract is lower than that in the atmospheric gas phase [5]. It is well known that oxygen at excessive tension gives an oxidative stress to mammalian cells, including embryos [1]. An oxygen concentration of 5 to $10 \%$ in the gas atmosphere has been reported to be optimal for the development of bovine embryos when they are cultured in vitro without feeder cells $[4,6,8,14-16,20]$. When bovine embryos were co-cultured with feeder cells such as oviduct cells, cumulus/granulosa cells, or other somatic cells, the optimal oxygen tension varied according to the cell type, medium and culture system itself $[6,8,19]$.

The in vitro insemination of bovine oocytes is usually performed by co-incubating spermatozoa with oocytes surrounded by cumulus cells. It is therefore expected that the optimal oxygen concentration in the gas atmosphere during in vitro insemination may also vary according to the in vitro insemination conditions. However, empirical protocols for the in vitro insemination of bovine oocytes commonly utilize atmospheric gas conditions of $5 \% \mathrm{CO}_{2}$ in air (approximately $20 \% \mathrm{O}_{2}$ ) with different details (i.e., media, medium volume, oocytes density, oil covering etc.) [10]. Few attempts have been made to determine the effects of the oxygen concentration during in vitro insemination on the fertilization of bovine oocytes $[10,18]$ or the subsequent embryo development in vitro [18]. In the present study, the hypothesis that the in vitro insemination of bovine oocytes under a low oxygen concentration $\left(5 \% \mathrm{O}_{2}\right)$, which is similar to the physiological level [5], would improve the fertilization rate and the subsequent embryonic development was tested by co-incubating in vitro matured oocytes with frozenthawed spermatozoa using our in vitro insemination procedure [12-14].

The in vitro maturation of follicular oocytes was performed as described previously [14]. Briefly, bovine cumulus-oocyte complexes (COCs) aspirated from small antral follicles of slaughterhouse-obtained bovine ovaries, were washed twice with HEPES-buffered Tyrode's medium (TALP-HEPES) [2]. The oocytes with morphologically normal ooplasm and with an intact cumulus were selected for culture. The in vitro maturation was accomplished in HEPES-buffered TCM199 (Gibco Laboratories, Grand Island, NY, U.S.A.) supplemented with $10 \%$ heat-treated fetal calf serum (Gibco), 0.02 units/m $l$ of follicle stimulating hormone (from porcine pituitary, Sigma), $1 \mu \mathrm{g} / \mathrm{m} l$ of estradiol-17 $\beta$ (Sigma), $0.2 \mathrm{mM}$ sodium pyruvate, and 50 $\mu \mathrm{g} / \mathrm{m} l$ of gentamicin sulfate. After being washed twice with the maturation medium, selected COCs were transferred to 50- $\mu l$ drops of maturation medium (10-13 COCs per drop) under paraffin oil in a 60-mm plastic dish (Falcon 1007, Becton Dickinson Labware, Lincoln Park, NJ, U.S.A.). They were then cultured for $22 \mathrm{hr}$ at $39^{\circ} \mathrm{C}$ in humidified air with $5 \% \mathrm{CO}_{2}$ (in a $\mathrm{CO}_{2}$ incubator; Napco 5100, Napco Scientific Co., Tualtin, OR, U.S.A.).

The in vitro insemination was conducted according to the procedure described elsewhere [14]. In brief, frozen sperm from a Holstein bull were thawed at $37^{\circ} \mathrm{C}$ for $30 \mathrm{sec}$, and subsequently layered onto a Percoll gradient (45 and 90\%). The Percoll gradient was centrifuged at $700 \times \mathrm{g}$ for $20 \mathrm{~min}$. After the top layers were removed, the sperm pellet was resuspended in $6 \mathrm{~m} l$ of modified Brackett and Oliphant isotonic medium [3] without bovine serum albumin (BSA), penicillin and streptomycin but with $1.7 \mu \mathrm{g} / \mathrm{m} l$ phenol red (Sigma) and $25 \mu \mathrm{g} / \mathrm{m} l$ gentamicin sulfate, which was designated as mBO medium [12]. They were then washed again by centrifugation at $500 \times \mathrm{g}$ for $5 \mathrm{~min}$. After the centrifugation and aspiration of the supernatant, the sperm pellet was resuspended to $10 \times 10^{6}$ cells $/ \mathrm{ml}$ in $\mathrm{mBO}$ medium. Initial in vitro insemination droplets were prepared with 50$\mu l$ of $\mathrm{mBO}$ medium containing $6 \mathrm{mg} / \mathrm{m} l$ of BSA (Fatty acid-free, Sigma) and $5 \mathrm{mM}$ theophylline (Sigma). The droplets were covered with paraffin oil in a $35-\mathrm{mm}$ plastic dish (Falcon 1008), and were kept at $39^{\circ} \mathrm{C}$ under 5 or $20 \%$ $\mathrm{O}_{2}$ for more than $3 \mathrm{hr}$ before use. Fifty $\mu \mathrm{l}$ of sperm suspension was introduced into the initial insemination droplet to give a final insemination droplet of $5 \times 10^{6}$ cells/ $\mathrm{m} l$ sperm concentration, $3 \mathrm{mg} / \mathrm{m} l \mathrm{BSA}$, and $2.5 \mathrm{mM}$ theophylline. COCs were then immediatley put into the 
Table 1. The effect of oxygen concentration in the gas atmosphere on the in vitro fertilization rate

\begin{tabular}{lcc}
\hline & \multicolumn{2}{c}{ Concentration of oxygen $(\%)$} \\
\cline { 2 - 3 } Item & 5 & 20 \\
\hline \multirow{2}{*}{ No. of replicates (oocytes) } & $5(111)$ & $5(129)$ \\
$\%$ of total fertilization & $92.4 \pm 5.2$ & $89.5 \pm 4.6$ \\
$\%$ of normal fertilization & $78.0 \pm 7.5$ & $78.5 \pm 5.3$ \\
$\%$ of polyspermy & $6.7 \pm 4.3$ & $4.7 \pm 3.5$ \\
\hline
\end{tabular}

Values are means $\pm \mathrm{SD}$ determined at $18 \mathrm{hr}$ after insemination.

above final insemination droplets (10 to 13 COCs per 100 $\mu l$ droplet), and co-incubated with sperm for $18 \mathrm{hr}$ at $39^{\circ} \mathrm{C}$ under 5 or $20 \% \mathrm{O}_{2}$. For the incubation under 5 and $20 \%$ $\mathrm{O}_{2}$, an oxygen-adjustable $\mathrm{N}_{2}-\mathrm{O}_{2}-\mathrm{CO}_{2}$ incubator $\left(5 \% \mathrm{O}_{2}\right.$ and $5 \% \mathrm{CO}_{2}$; BPN 110, Tabai Espec Co., Osaka, Japan) and a $\mathrm{CO}_{2}$ incubator $\left(5 \% \mathrm{CO}_{2}\right.$ in air) were used, respectively. After the co-incubation with sperm, the COCs were transferred to a $10 \mathrm{ml}$ conical tube (Falcon 2059) and vortexed for 3 to $4 \mathrm{~min}$ in $1 \mathrm{ml}$ of TALP-HEPES to remove their cumulus cells.

The first experiment was carried out to determine the effect of oxygen concentration in the gas atmosphere during in vitro insemination on the fertilization rate. The cumulusfree oocytes were fixed with a mixture of ethanol and acetic acids (3:1), and stained with $1 \%$ aceto-orcein. The evaluation of the fertilization was made under a phasecontrast microscope. The oocytes were considered as fertilized when they had an enlarged sperm head(s) or male pronucleus(ei) with corresponding sperm tail(s). The percentage of normal fertilization was determined as the ratio of the oocytes with a pair of pronuclei and corresponding sperm tail to the total number of oocytes evaluated. The results are shown in Table 1. There were no significant differences between the 5 and $20 \% \mathrm{O}_{2}$ concentration preparations in any of the criteria examined (P>0.1; Student's $t$-test).

The effect of oxygen concentration in the gas atmosphere during in vitro insemination on the subsequent embryonic development was examined in the next experiment. After in vitro insemination under 5 or $20 \% \mathrm{O}_{2}$, the cumulus-free oocytes (presumptive zygotes) were washed five times with a protein-free chemically defined medium. They were then cultured in a $40-\mu l$ droplet of the defined medium (25 to 30 zygotes per droplet) covered with paraffin oil for 6 days (about $154 \mathrm{hr}$ ) at $39^{\circ} \mathrm{C}$ under a gas atmosphere with $5 \%$ $\mathrm{CO}_{2}$ and $5 \% \mathrm{O}_{2}$ using the oxygen-adjustable $\mathrm{N}_{2}-\mathrm{O}_{2}-\mathrm{CO}_{2}$ incubator. A modified synthetic oviduct fluid medium supplemented with $1 \mathrm{mM}$ glutamine (Sigma), 12 essential amino acids for basal medium Eagle (Flow Laboratories, Irvine, Scotland), 7 non-essential amino acids for minimum essential medium (Flow), $10 \mu \mathrm{l} / \mathrm{m} \mathrm{l}$ of insulin (Sigma), and $1 \mathrm{mg} / \mathrm{ml}$ of polyvinyl alcohol (Sigma), designated as mSOFai [14], was used as a chemically defined medium. Seven days (about $172 \mathrm{hr}$ ) after insemination, the cleavage rate and the percentage of presumptive zygotes developed to blastocysts were determined. The total cell numbers of all blastocysts were examined using an air-dry procedure [12]. As shown in Table 2, the in vitro insemination under $5 \% \mathrm{O}_{2}$ yielded a higher percentage of blastocysts than that under $20 \% \mathrm{O}_{2}(\mathrm{P}<0.05$; Student's $t$-test $)$. However, there was no difference between the 5 and $20 \% \mathrm{O}_{2}$ preparations in the cleavage rate or total cell number per blastocyst $(\mathrm{P}>0.05)$.

No remarkable effect of oxygen concentration in the gas phase was detected on the fertilization rate under the present experimental conditions. This result is in agreement with the finding reported by Van der Westerlaken et al. [18]. In contrast, Pinyopummintr and Bavister [10] demonstrated a lower fertilization rate after culturing bovine oocytes through in vitro maturation and insemination in $5 \% \mathrm{O}_{2}$ compared with that in $20 \% \mathrm{O}_{2}$. They did not determine the effect of oxygen concentration during the in vitro insemination separately from in vitro maturation. It is thus not possible to compare the present data with their results.

In the present experiment, $5 \% \mathrm{O}_{2}$ during the in vitro insemination improved the subsequent embryonic development to blastocysts. In contrast, Van der Westerlaken et al. [18] reported that $5 \% \mathrm{O}_{2}$ during in vitro insemination significantly increased the cleavage rate, but had no obvious beneficial effect on the percentage of blastocysts compared with $20 \% \mathrm{O}_{2}$ (24.6 vs. $15.7 \%$, respectively). The discrepancy is obscure, since they did not describe the details of the in vitro insemination procedure in their abstract paper [18].

The reason(s) for the improved developmental potential to the blastocyst stage under the present in vitro insemination in $5 \% \mathrm{O}_{2}$ is not clear. However, it has been

Table 2. The effect of oxygen concentration in the gas atmosphere during in vitro insemination on the subsequent in vitro development of presumptive zygotes

\begin{tabular}{lcc}
\hline \multirow{2}{*}{ Item } & \multicolumn{2}{c}{ Concentration of oxygen $(\%)$} \\
\cline { 2 - 3 } & 5 & 20 \\
\hline \multirow{2}{*}{ No. of replicates (zygotes) } & $5(150)$ & $5(143)$ \\
\% of cleaved zygotes & $79.9 \pm 3.7$ & $77.3 \pm 5.7$ \\
$\%$ of blastocysts & $34.4 \pm 6.7^{\mathrm{a})}$ & $24.7 \pm 6.2^{\mathrm{b})}$ \\
Total cell numbers per blastocyst $(\mathrm{N})$ & $193.4 \pm 67.1(52)$ & $196.5 \pm 63.1(36)$ \\
\hline
\end{tabular}

Values are means \pm SD determined at around $172 \mathrm{hr}$ after insemination. a), b) Values with different superscripts denote a significant difference $(\mathrm{P}<0.05)$. 
shown that the blastocyst formation rate in mice embryos was significantly decreased after a 1-hr exposure of pronuclear embryos to $20 \% \mathrm{O}_{2}[9,17]$. It is likely that the present in vitro insemination procedure in $5 \% \mathrm{O}_{2}$ might reduce the oxidative stress and/or production of reactive oxygen species (ROS) [1,7] resulting in an improvement of the subsequent embryonic development as a latent effect. Alternatively, the time course of the in vitro fertilization in $5 \% \mathrm{O}_{2}$ might differ from that in $20 \% \mathrm{O}_{2}$. The delay in the sperm penetration causes the aging of oocytes and reduces the viability of fertilized oocytes [11]. Further experiments on the oxidative stress/production of ROS during in vitro insemination and the time course of fertilization are needed to clarify the beneficial effect of in vitro insemination under $5 \% \mathrm{O}_{2}$ on fertilization and subsequent embryonic development.

In conclusion, the present results demonstrated that lowering the oxygen concentration from 20 to $5 \%$ during in vitro insemination does not affect the fertilization rate, but improves the subsequent embryonic development to the blastocyst stage under the present experimental conditions.

ACKNOWLEDGMENTS. This study was supported by a Grant-in-Aid for Scientific Research (No. 09660296) from the Ministry of Education, Science, Sports and Culture, Japan to Y. Takahashi. The authors thank the staff of the Ebetsu Meat Inspection Center for the collection of bovine ovaries, and the Hokkaido Livestock Improvement Association for the donation of frozen bull sperm.

\section{REFERENCES}

1. Bavister, B. D. 1995. Human Reprod. Update 1: 91-148.

2. Bavister, B. D., Leibfried, M. L. and Lieberman, G. 1983. Biol. Reprod. 28: 235-247.
3. Brackett, B. G. and Oliphant, G. 1975. Biol. Reprod. 12: 260-274.

4. Carolan, C., Lonergan, P., Van Langendonckt, A. and Mermillod, P. 1995. Theriogenology 43: 1115-1128.

5. Fischer, B. and Bavister, B. D. 1993. J. Reprod. Fertil. 99: 673-679.

6. Fukui, Y., McGowan, L. T., James, R. W., Pugh, P. A. and Tervit, H. R. 1991. J. Reprod. Fertil. 1991; 92: 125-131.

7. Goto, Y., Noda, Y., Mori., T. and Nakano, M. 1993. Free Radic. Biol. Med. 15: 69-75.

8. Nagao, Y., Saeki, K., Hoshi, M. and Kainuma, H. 1994. Theriogenology 41: 681-687.

9. Pabon, J. E. Jr., Findley, W. E. and Gibbons, W. E. 1989. Fertil. Steril. 51: 896-900.

10. Pinyopummintr, T. and Bavister, B. D. 1995. Theriogenology 44: 471-477.

11. Susko-Parrish, J., Nuttleman, J. and Leibfried-Rutledge, M. L. 1991. Biol. Reprod. 44 (Suppl. 1): 156 (Abstr. 414).

12. Takahashi, Y. and First, N. L. 1992. Theriogenology 37: 963-978.

13. Takahashi, Y. and First, N. L. 1993. Anim. Reprod. Sci. 34: $1-18$.

14. Takahashi, Y., Hishinuma, M., Matsui, M., Tanaka, H. and Kanagawa, H. 1996. J. Vet. Med. Sci. 58: 897-902.

15. Tervit, H. R., Whittingham, D. G. and Rowson, L. E. A. 1972. J. Reprod. Fertil. 30: 493-497.

16. Thompson, J. G. E., Simpson, A. C., Pugh, P. A., Donnelly, P. E. and Tervit, H. R. 1990. J. Reprod. Fertil. 89: 573-578.

17. Umaoka, Y., Noda, Y., Narimoto, K. and Mori, T. 1992. Mol. Reprod Dev. 31: 28-33.

18. Van der Westerlaken, L. A. J., Van der Vlugt, J. J., De Wit, A. A. C. and Van der Schans, A. 1992. Theriogenology 37: 312 (Abstr.).

19. Voelkel, S. A. and Hu, Y. X. 1992. Theriogenology 37: 11171131.

20. Yang, B. K., Yang, X. and Foote, R. H. 1994. J. Reprod. Dev. 40: 197-205. 